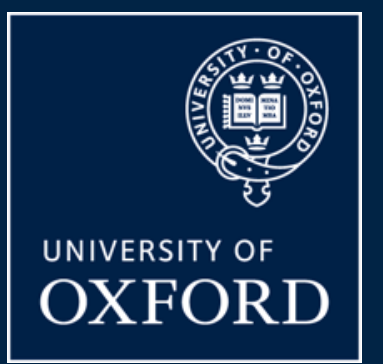

\title{
OpenSky: A Swiss Army Knife for Air Traffic Security Research
}

\author{
Martin Strohmeier 1 \\ Matthias Schäfer ${ }^{2}$ \\ Markus Fuchs ${ }^{4}$ \\ Vincent Lenders ${ }^{3}$ \\ Ivan Martinovic ${ }^{1}$ \\ 1 University of Oxford, UK \\ ${ }^{2}$ University of Kaiserslautern, Germany \\ ${ }^{3}$ armasuisse, Switzerland \\ ${ }^{4}$ SeRo Systems, Germany
}

September 15, 2015 


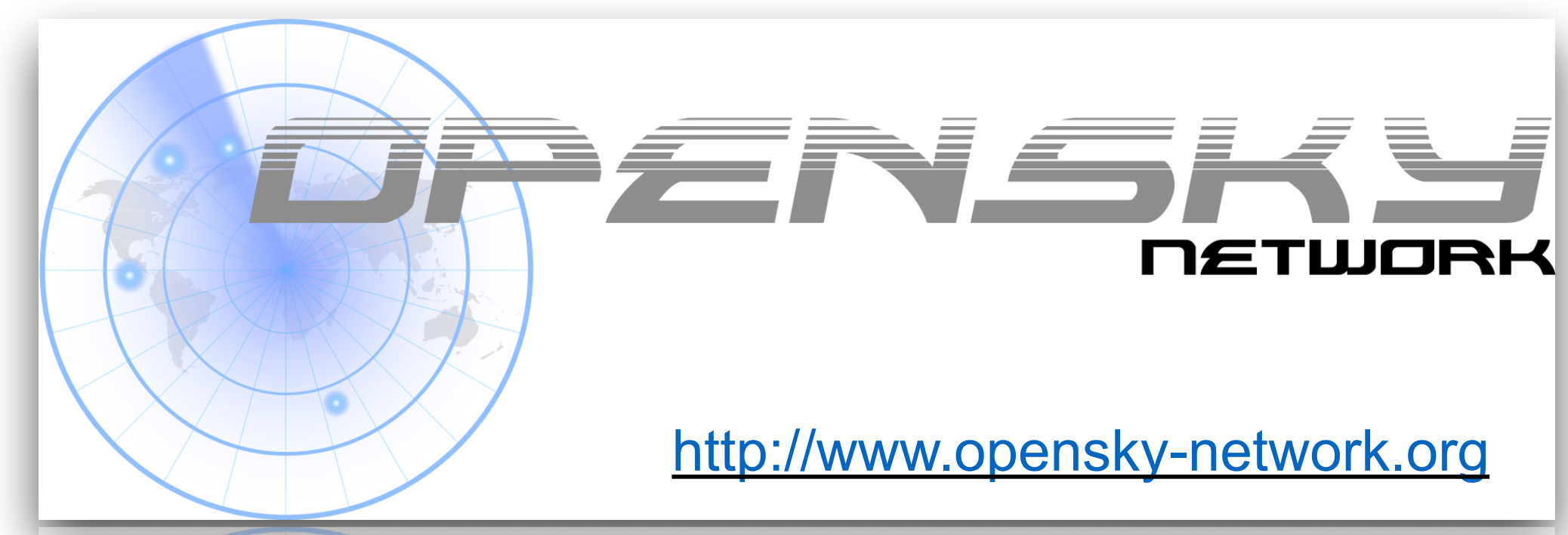

- Original motivation: Security research into ADS-B

- Basic testing with single sensors in our lab

- Collaboration across countries and labs, sharing of data

- Development of the OpenSky idea: formalisation and development of adequate research and sharing infrastructure

- Registered association since 2014 


\section{Who and What is OpenSky?}

- A large-scale ADS-B sensor network (online Jan. 2013)

- Cheap ADS-B sensors distributed (mostly) in Europe

- Receivers are connected over the Internet

- Access to raw ADS-B data and PHY-layer information

J. Schweizerische Eidgenossenschaft armasuisse

Confédération suisse

Confederazione Svizzera

Confederaziun svizra
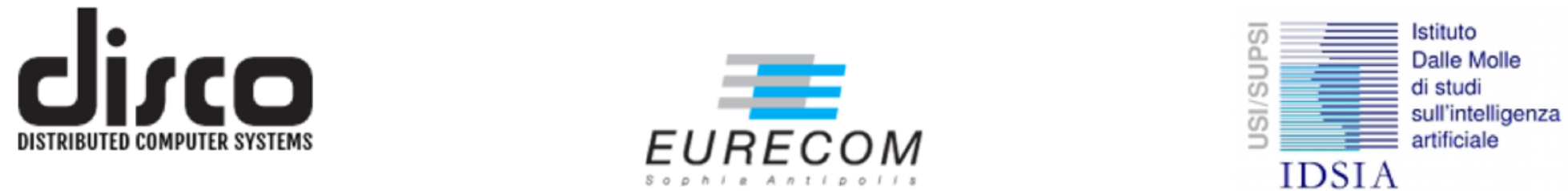

indea

networks

EURECOM

IDSIA
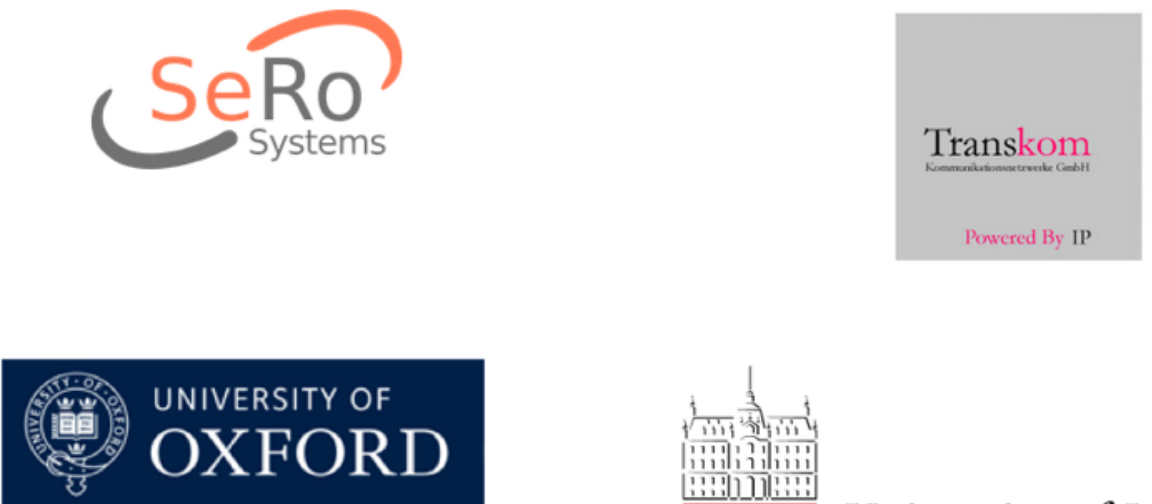

CWI 


\section{OpenSky Basis}
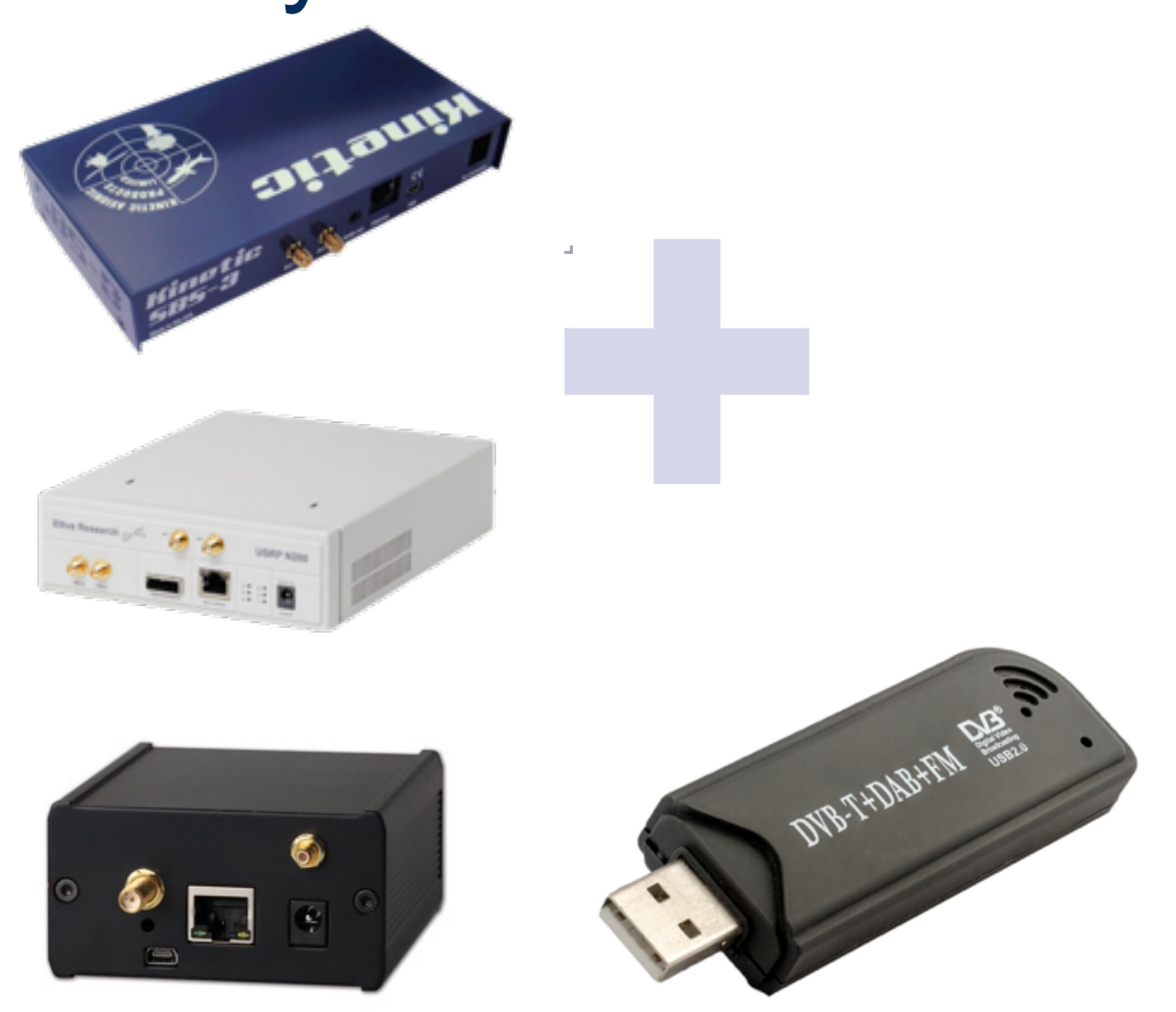

Various off-the-shelf sensors installed by motivated volunteers.

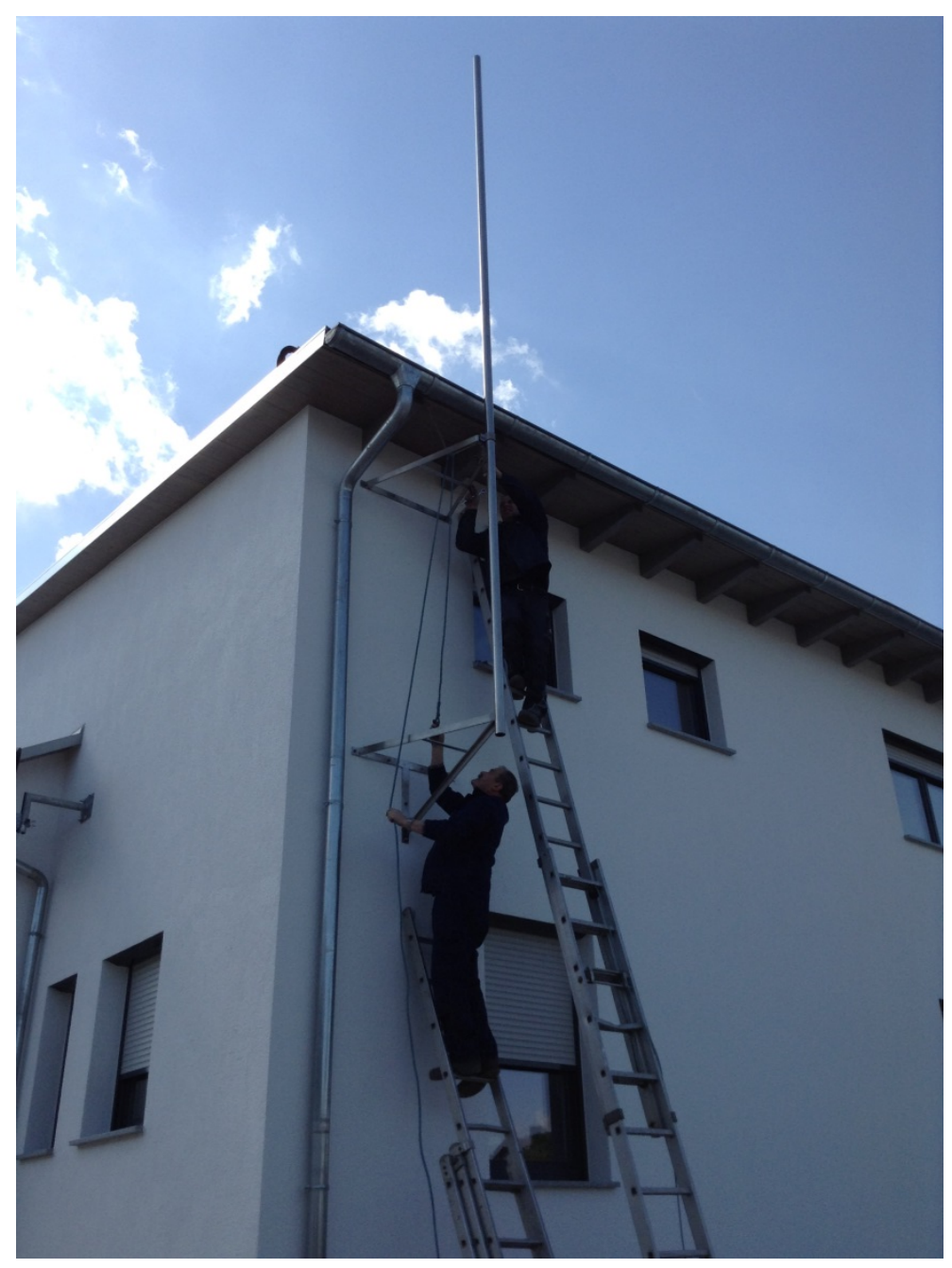




\section{OpenSky Frontend}

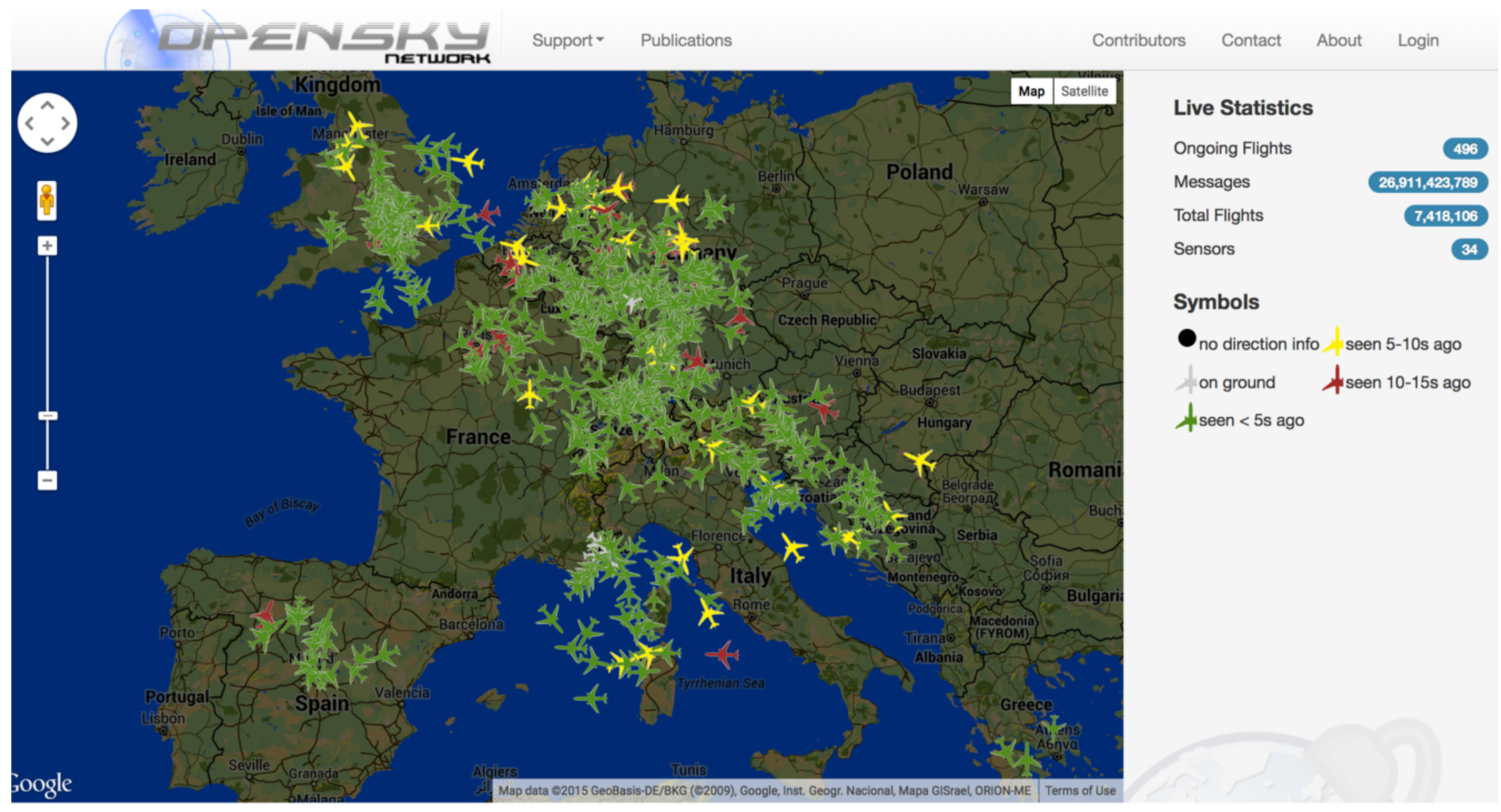




\section{OpenSky Backend}

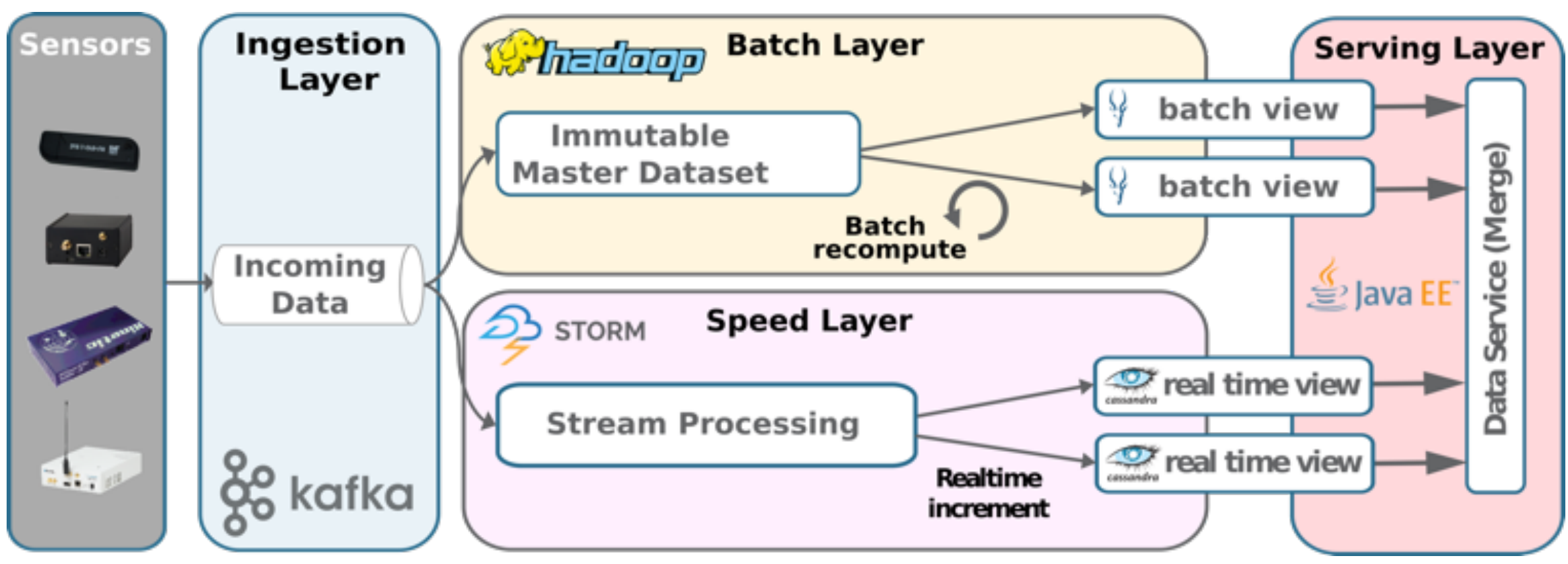

- Move from RDMS architecture to big data system

- Four horizontally scalable layers

- Enables real-time processing of all received messages in $<20 \mathrm{~ms}$, and fast large-scale analysis over all data 


\section{Current OpenSky Coverage}

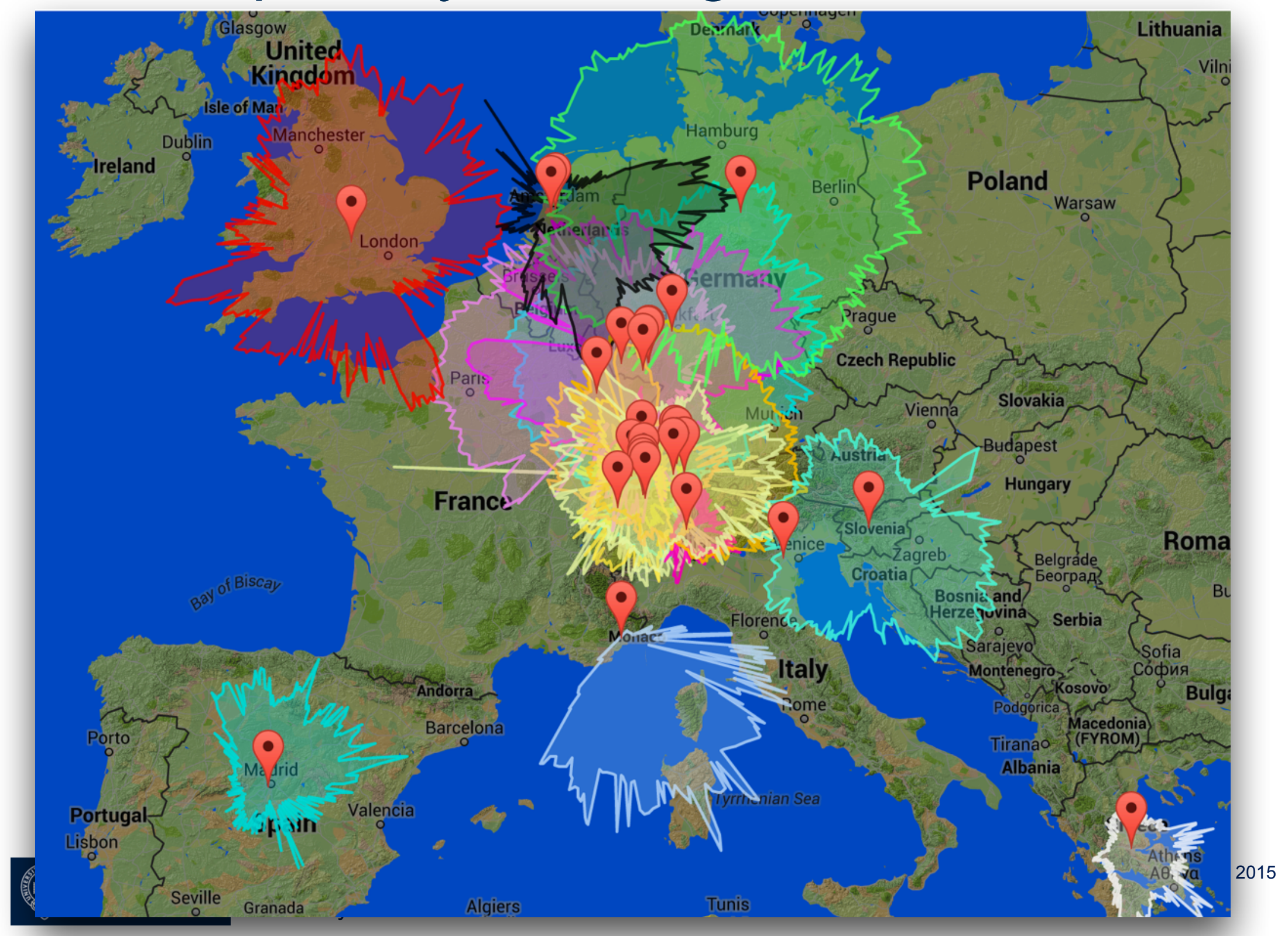




\section{Example of an OpenSky Dataset}

- Contents

- ID

- Velocity

- Position

- ...

- Meta Data

- Physical layer data

- RSS

- Loss

- SNR

- Timestamps

- Sensor ID

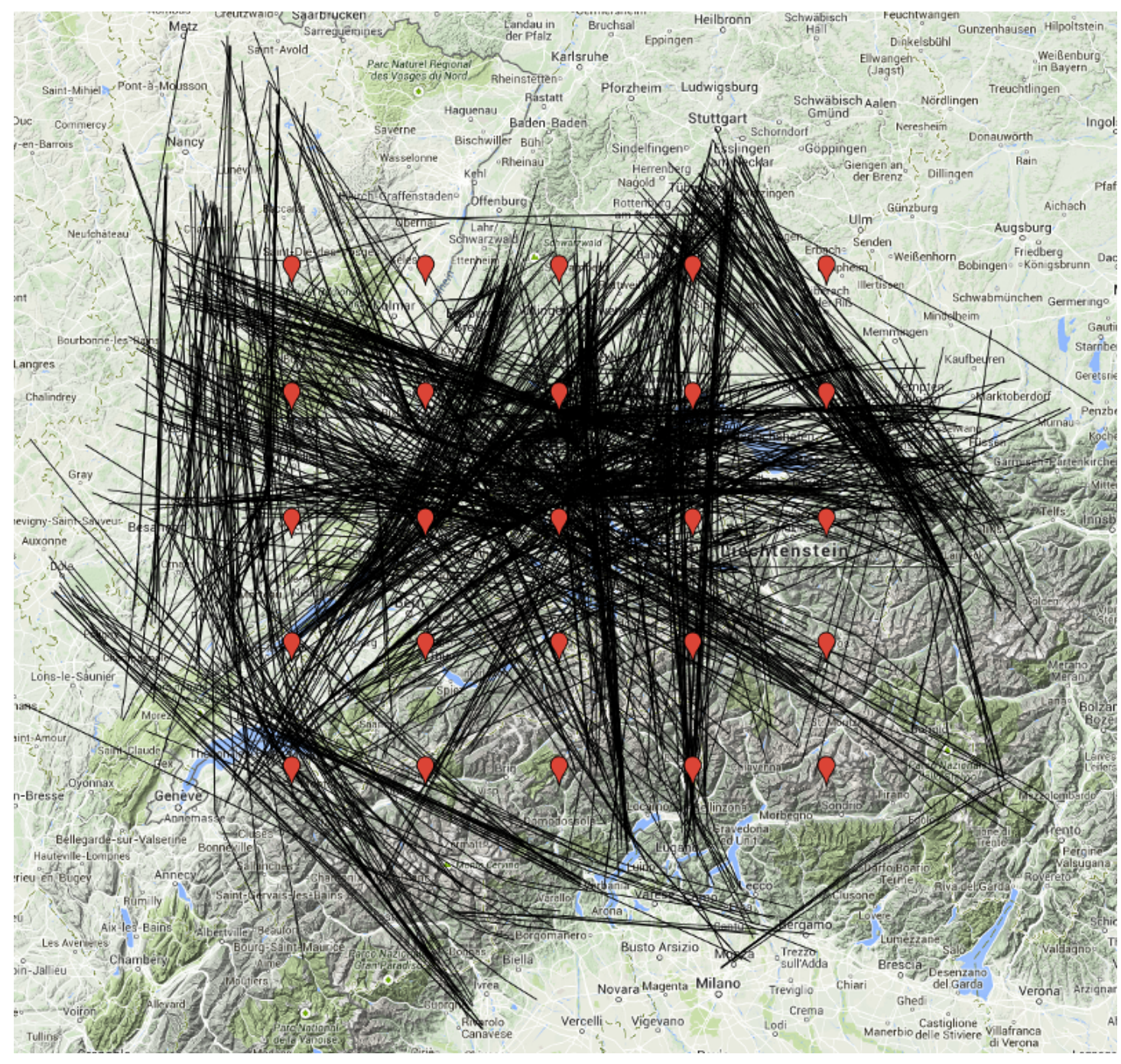

DASC 2015: OpenSky - A Swiss Army Knife for Air Traffic Security Research
September 15, 2015

Page 8 


\section{ADS-B Channel Analysis with OpenSky}

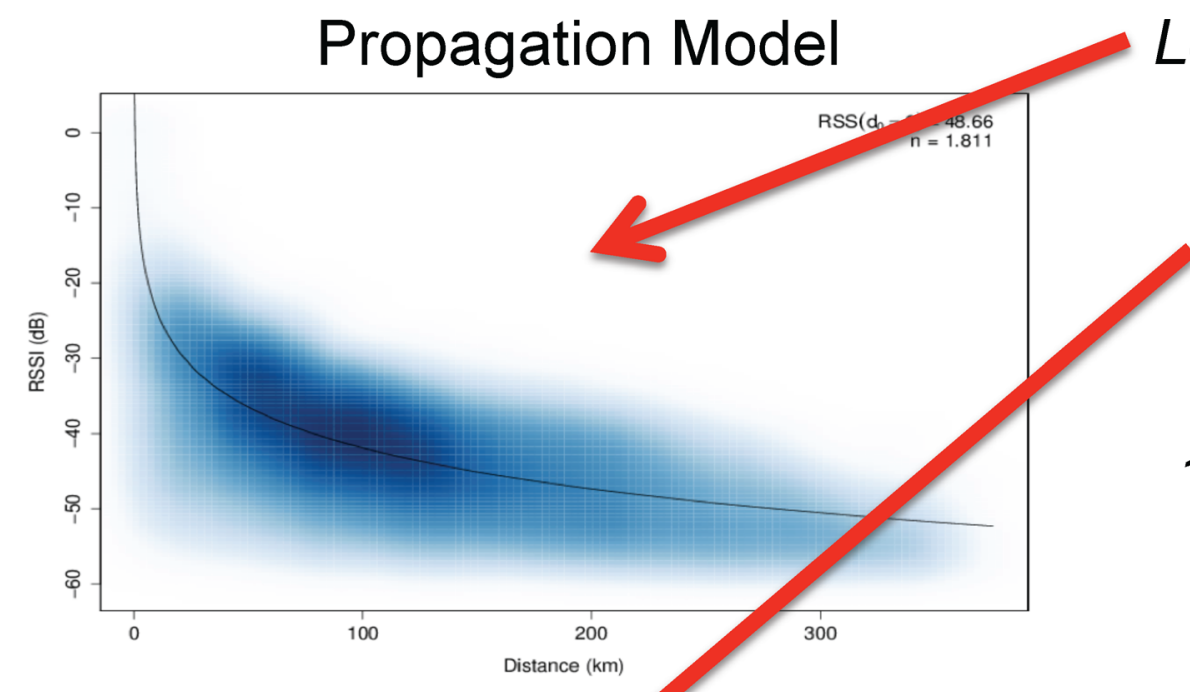

Log-distance Path Loss Model (LDPL)

Doughnut effect: noticeable drop in reception quality of messages sent in close proximity to a receiver.

$1090 \mathrm{MHz}$ channel utilization is very high 60 aircraft $\rightarrow 40 \%$ message loss

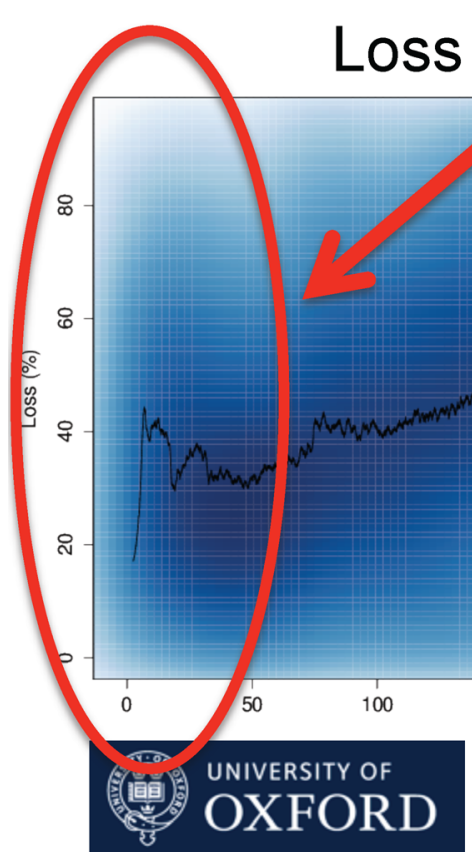

Distance $(\mathrm{km})$

DASC 2015: OpenSky - A Swiss Army Knife for Air Traffic

Security Research

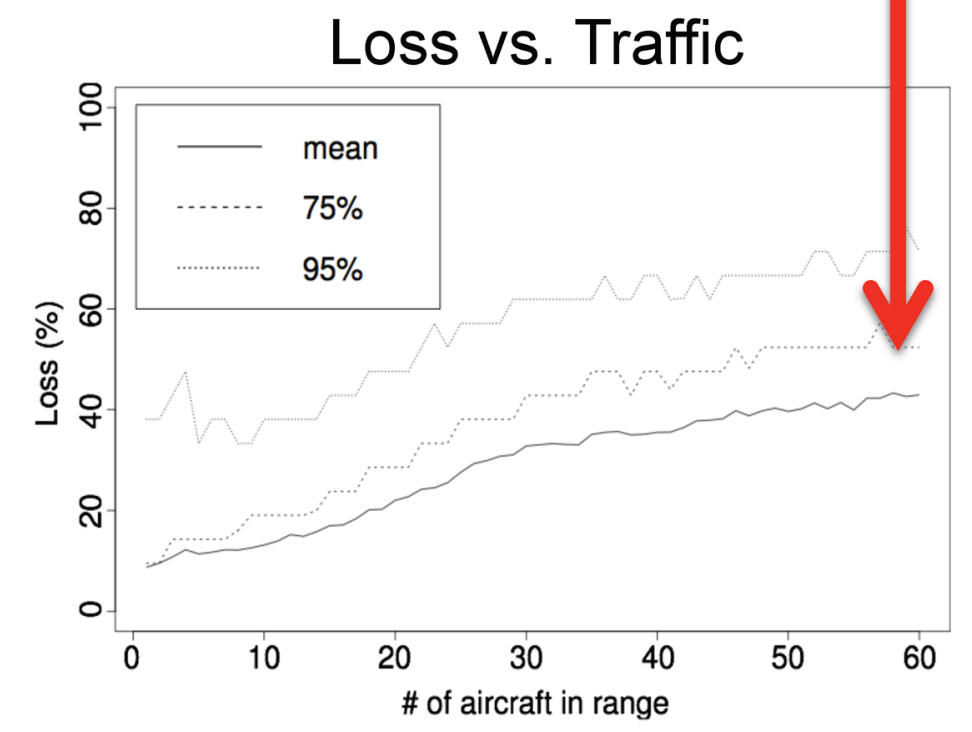




\section{Exemplary Security Research with OpenSky}

- Aircraft Location Verification

- Secure Track Verification

- Physical Layer Intrusion Detection

- Transponder Fingerprinting

- Event Detection

- For all the details, read the papers on the OpenSky website! 


\section{Some Attacker Models}

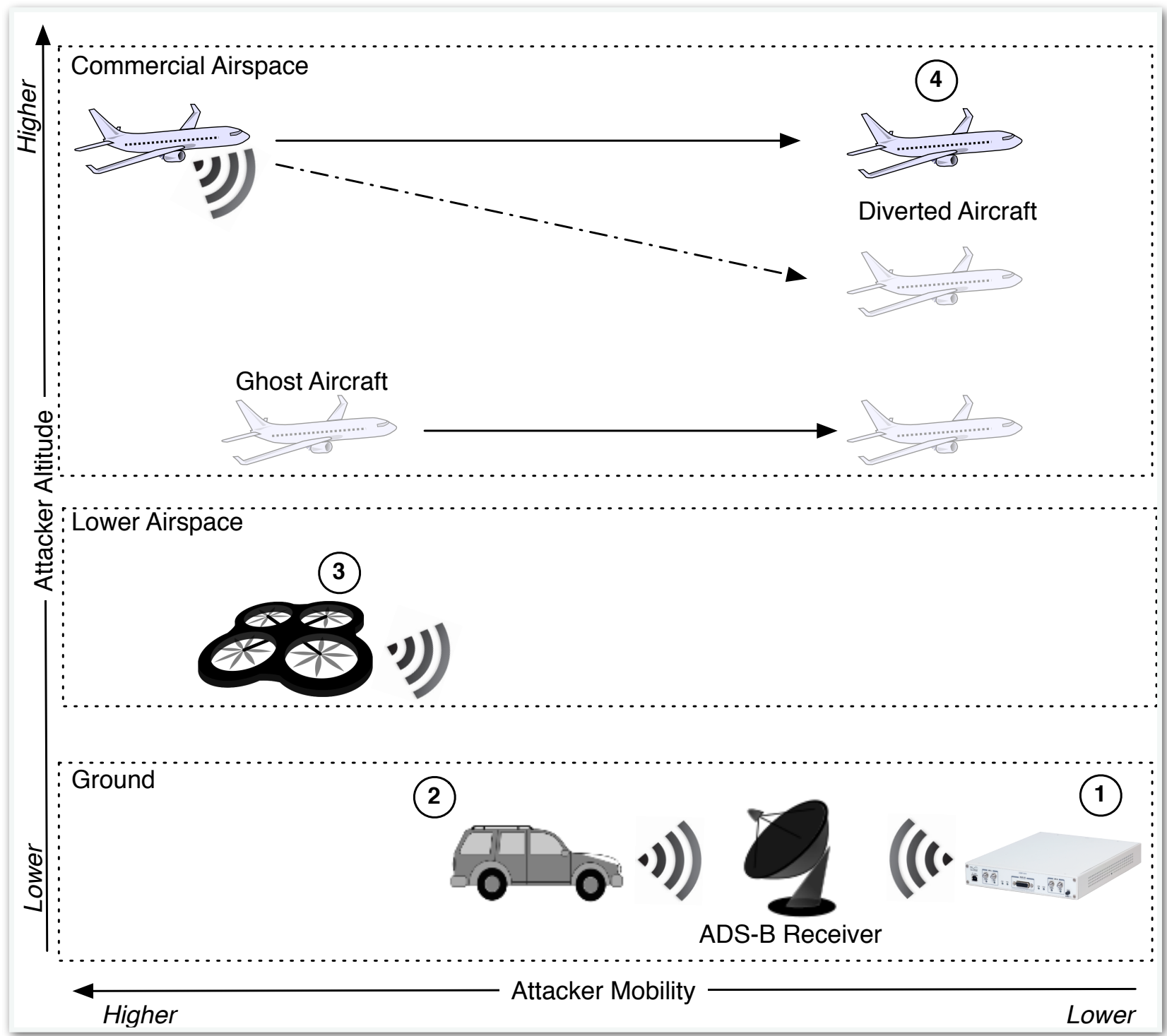

DASC 2015: OpenSky - A Swiss Army Knife for Air Traffic

Security Research 


\section{Aircraft Location Verification}




\section{Aircraft Location Verification: Multilateration}

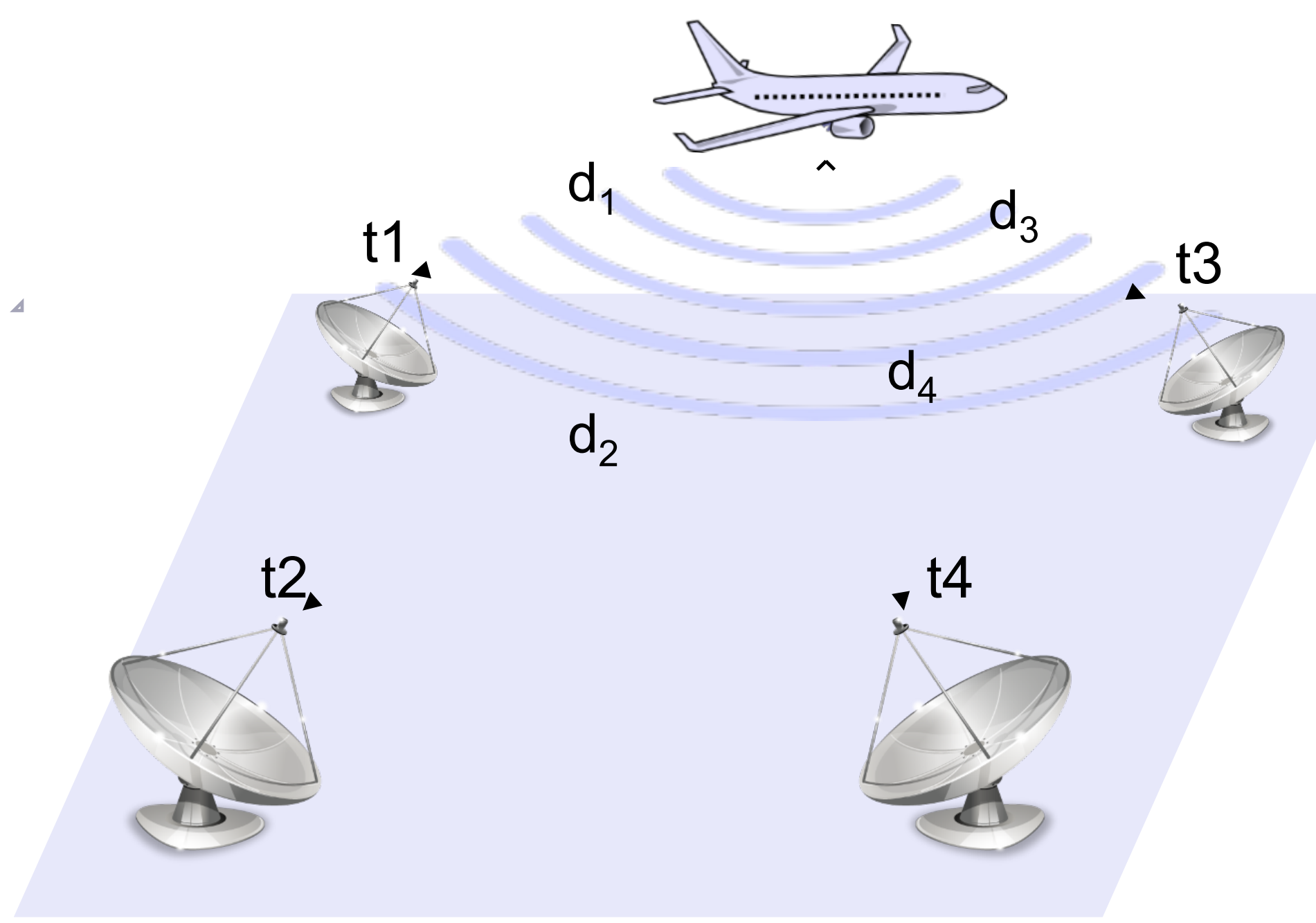




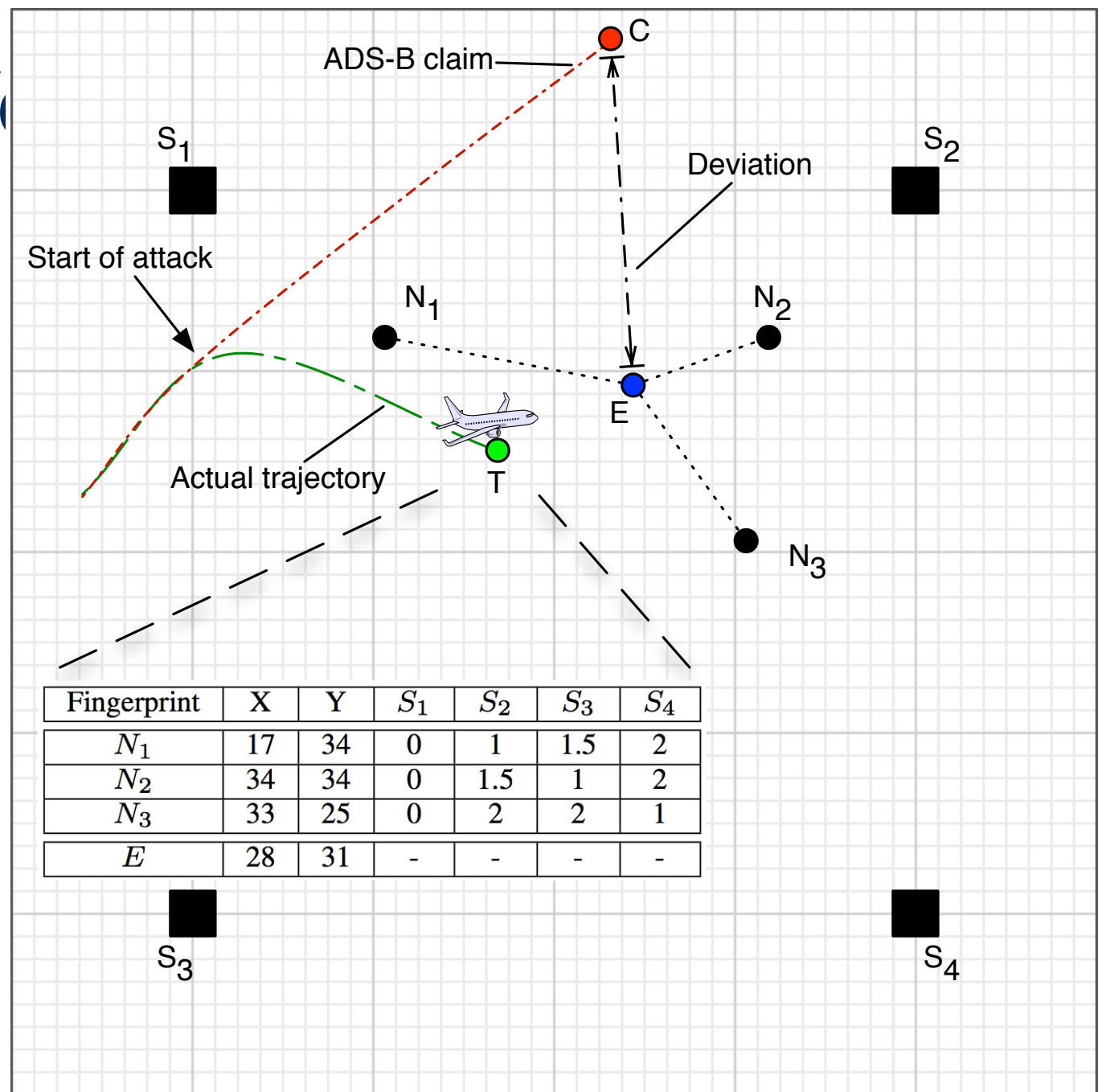

[1] "Lightweight Location Verification in Air Traffic Surveillance Networks."

Martin Strohmeier, Vincent Lenders and Ivan Martinovic. In Proceedings of the 1st ACM Workshop on Cyber-Physical System Security (CPSS '15). April, 2015. 


\section{Secure Track Verification}




\section{Secure Track Verification}

- New approach, exploiting the inherent mobility of aircraft

- Use sequences of location claims, measure differences in propagation delay to receivers

- Detect any deviation

- Not dependent on tight synchronisation and hardware

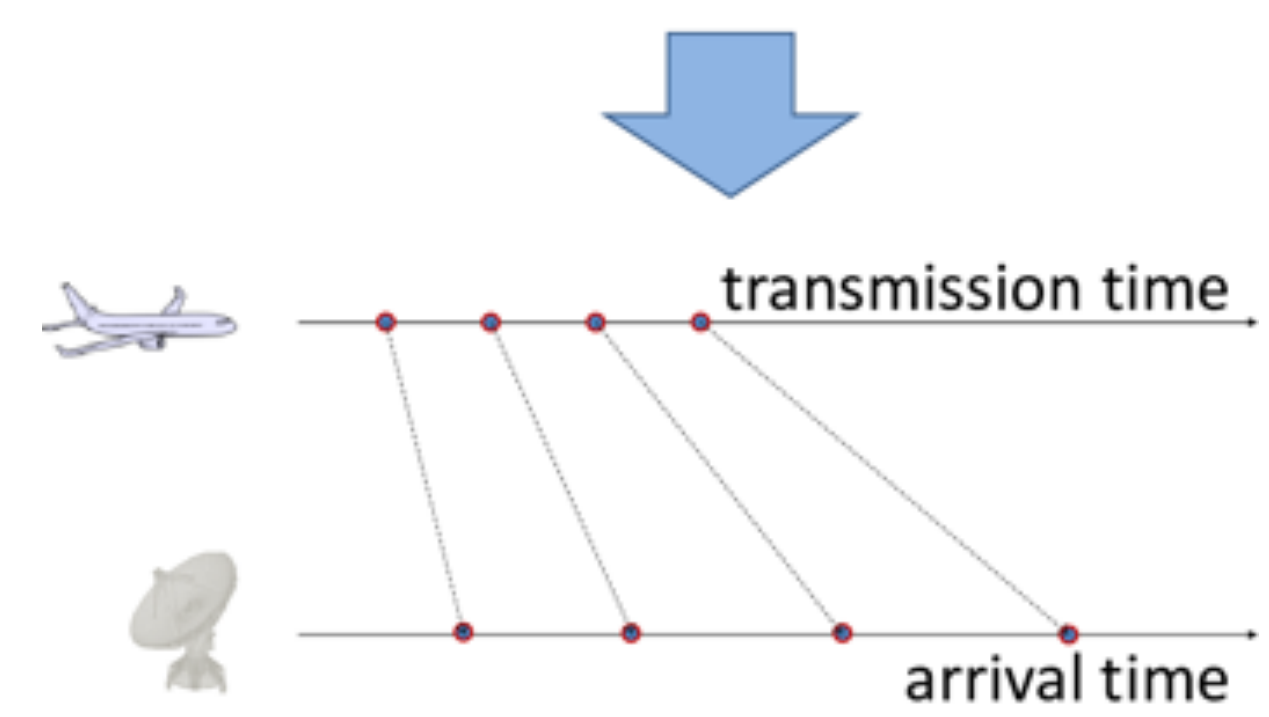




\section{Secure Track Verification}

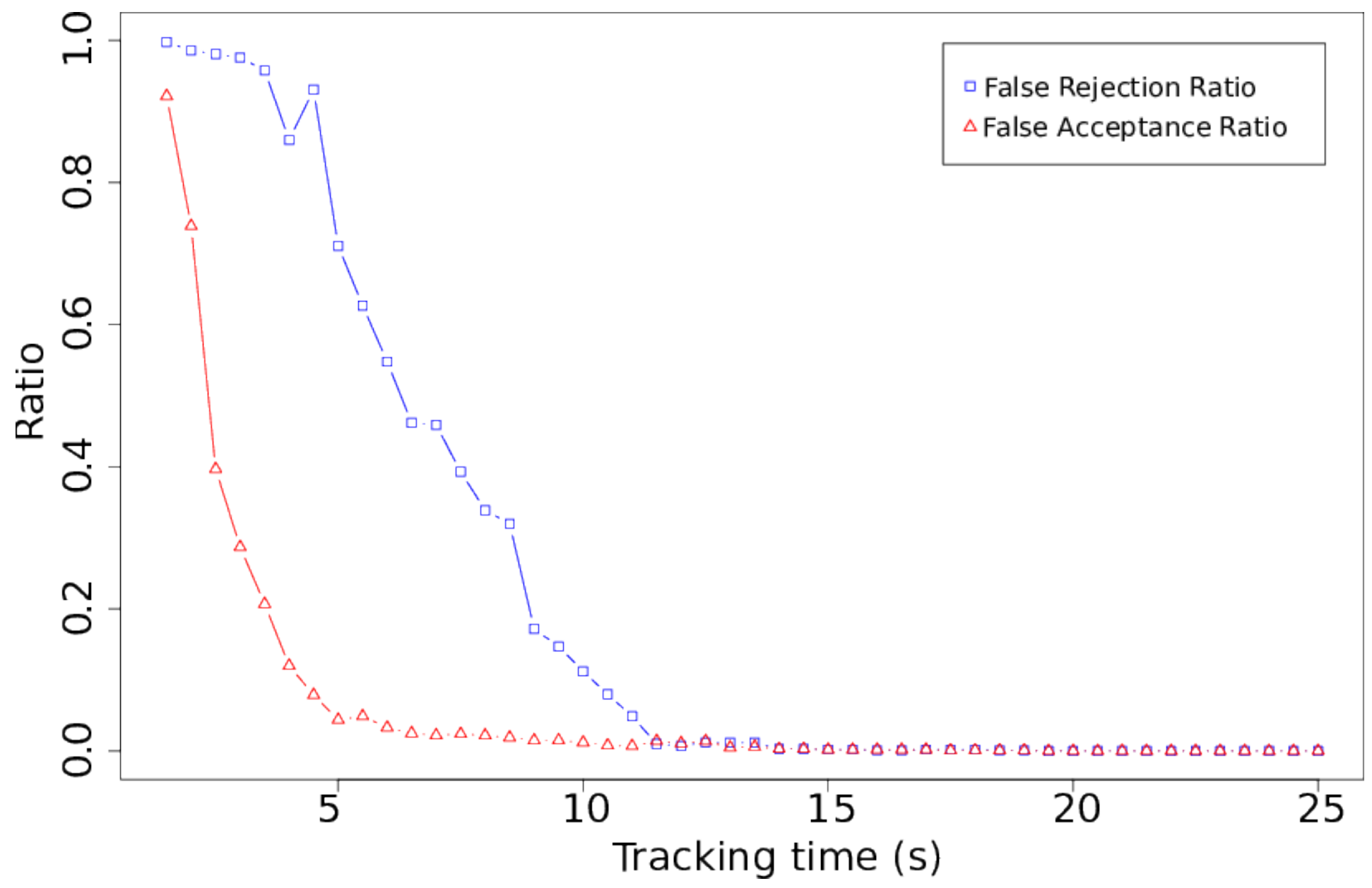

[2] "Secure Track Verification." Matthias Schäfer, Vincent Lenders and Jens B Schmitt. In IEEE Symposium on Security and Privacy (S\&P) May 2015. 


\section{PHY-Layer Intrusion Detection}




\section{Anomaly Detection}

- One-class classification

- Simulation of different attacker types

- constant sending strength

- random sending strength

- adaptive sending strength

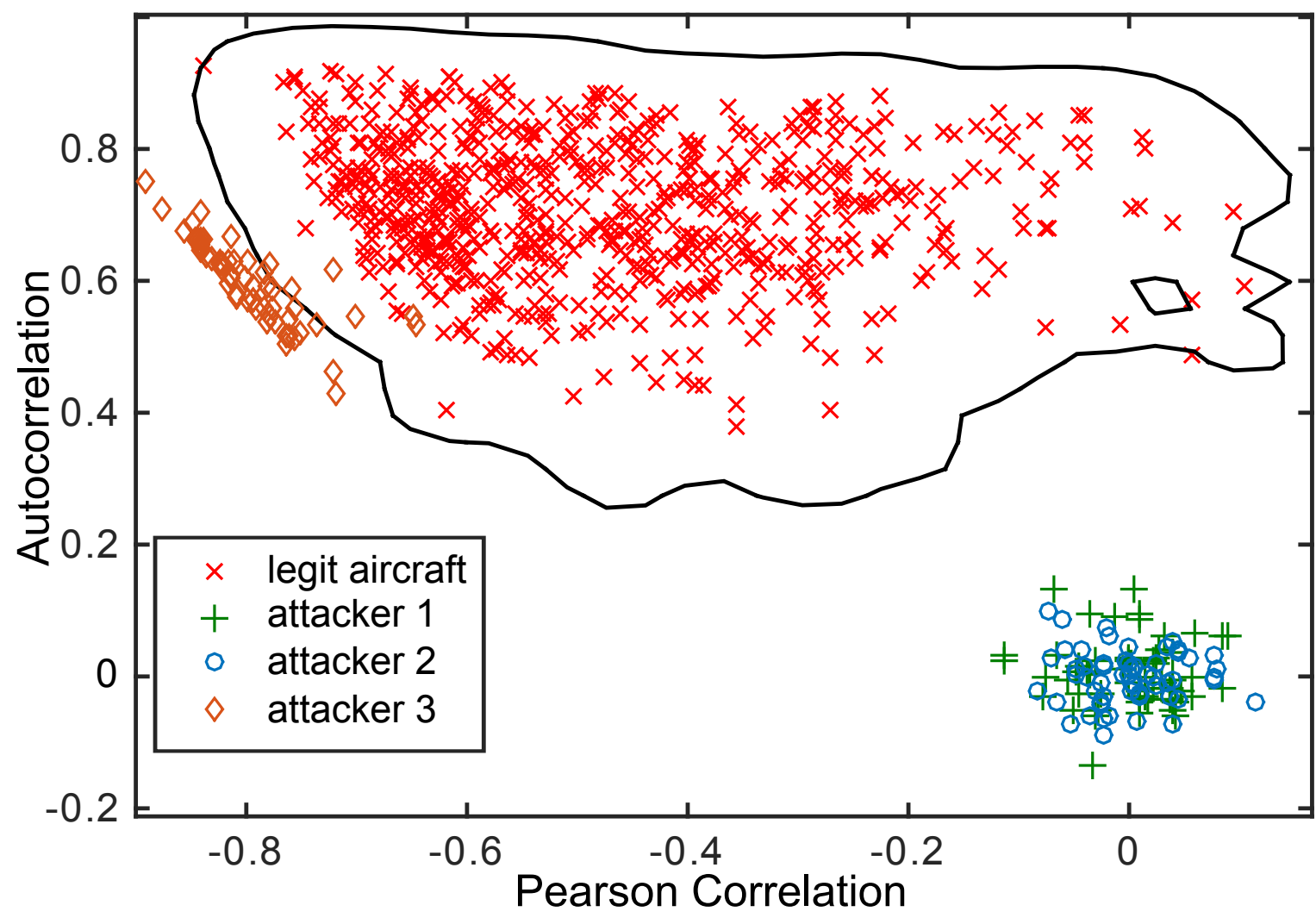

[3] "Intrusion Detection for Airborne Communication using PHY-Layer Information." Martin Strohmeier, Vincent Lenders and Ivan Martinovic. In Detection of Intrusions and Malware, and Vulnerability Assessment (DIMVA). July, 2015. 


\section{Transponder Fingerprinting}




\section{Transponder Fingerprinting}

- Different ADS-B transponder types / implementations used in the commercial aviation market.

- Several features based on random message inter-arrival times.
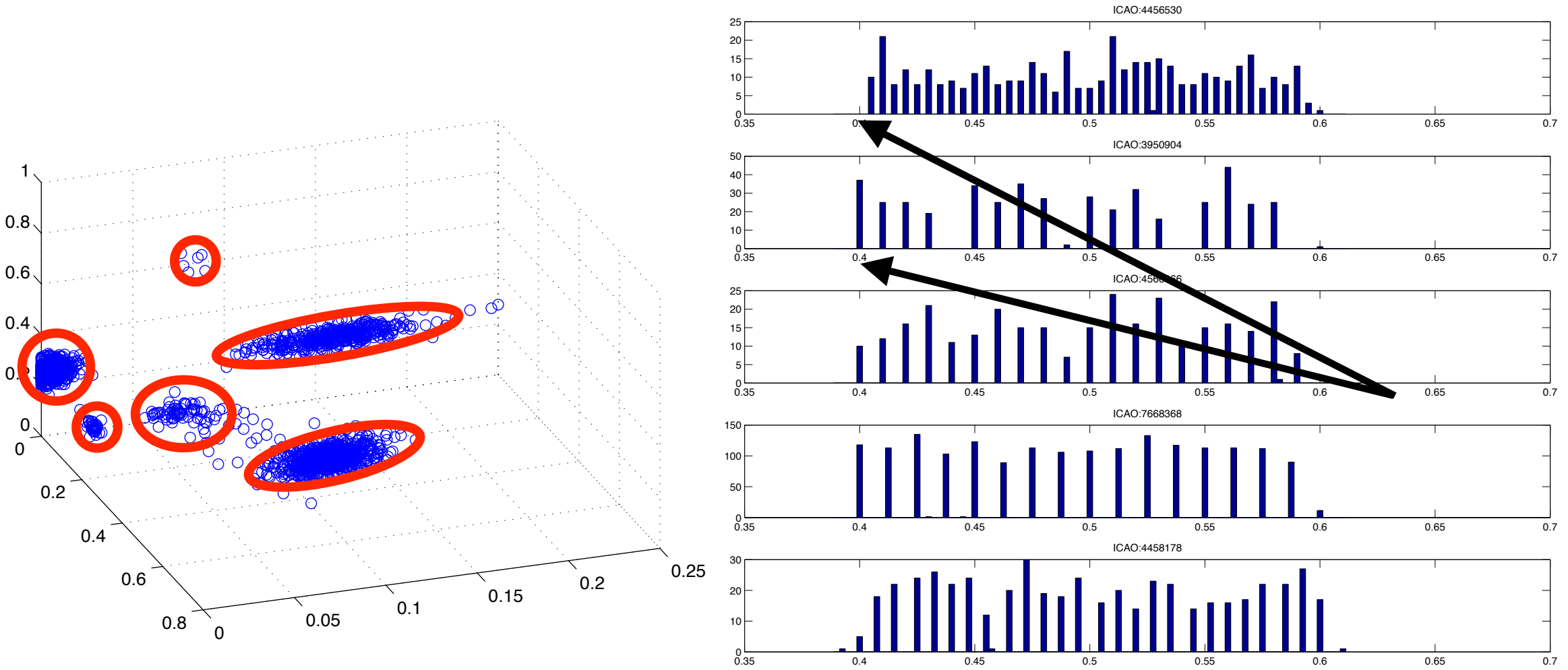


\section{Transponder Fingerprinting}

- 6 main types. With 100 samples, prediction accuracy of $99.91 \%$

- Some special cases with unique feature combinations, making aircraft potentially identifiable, even when using pseudonyms / not broadcasting their ID.

\begin{tabular}{|c|c|c|c|c|c|c|c|}
\hline Feature & \# Slots & Slot width & Inter-slot width & Missing slots & No width slots & First slot & Last slot \\
\hline \hline Type 1a & 39 & $\pm 0.00025 \mathrm{~s}$ & $0.005 \mathrm{~s}$ & No & No & $0.405 \mathrm{~s}$ & $0.595 \mathrm{~s}$ \\
\hline Type 1b & 41 & $\pm 0.00025 \mathrm{~s}$ & $0.005 \mathrm{~s}$ & No & Yes & $0.40 \mathrm{~s}$ & $0.60 \mathrm{~s}$ \\
\hline Type 2 & 16 & $\pm 0.001 \mathrm{~s}$ & $0.01 \mathrm{~s}$ & Yes & No & $0.40 \mathrm{~s}$ & $0.59 \mathrm{~s}$ \\
\hline Type 3 & 20 & $\pm 0.0005 \mathrm{~s}$ & $0.01 \mathrm{~s}$ & No & No & $0.40 \mathrm{~s}$ & $0.59 \mathrm{~s}$ \\
\hline Type 4 & 16 & $\pm 0.0015 \mathrm{~s}$ & $0.125 \mathrm{~s}$ & No & Yes & $0.40 \mathrm{~s}$ & $0.60 \mathrm{~s}$ \\
\hline Type 5 & 26 & $+0.00016 \mathrm{~s}$ & $0.008 \mathrm{~s}$ & No & No & $0.40 \mathrm{~s}$ & $0.61 \mathrm{~s}$ \\
\hline
\end{tabular}

[4] "On Passive Data Link Layer Fingerprinting of Aircraft Transponders." Martin Strohmeier and Ivan Martinovic. In 1st ACM Workshop on Cyber-Physical Systems Security \& Privacy (CPS-SPC). October, 2015. 


\section{Event Detection}




\section{Event Detection}

- Time series analysis to identify anomalies.

- Combine OpenSky ADS-B sensor data with publicly available databases about 24-bit ICAO identifiers, aircraft types and airline to track various types of activity.

- Data from 2 OpenSky sensors closest to Davos / Zurich:

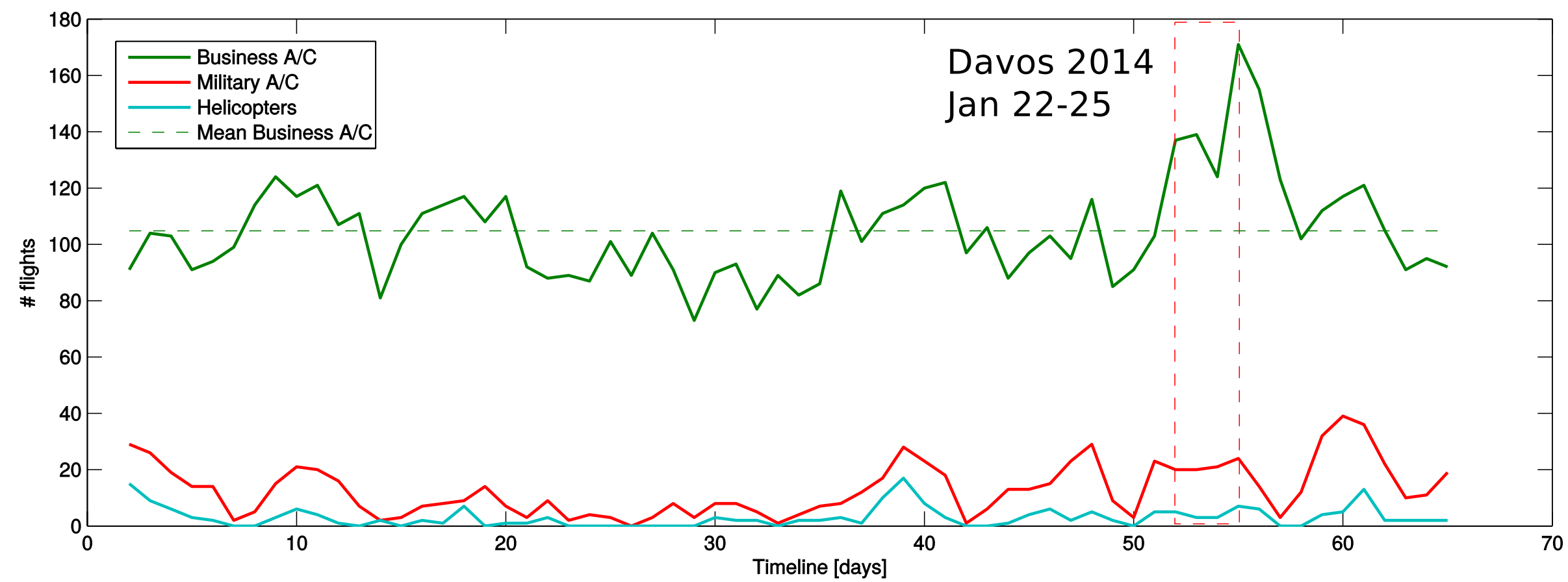




\section{Event Detection}

- $>70 \%$ increase from mean and $45 \%$ increase over previous peaks.

- Pitfalls:

- Data quality / consistency.

- Need to take long-term trends into account / compare to recent data.

- Doesn't tell us what is going on!

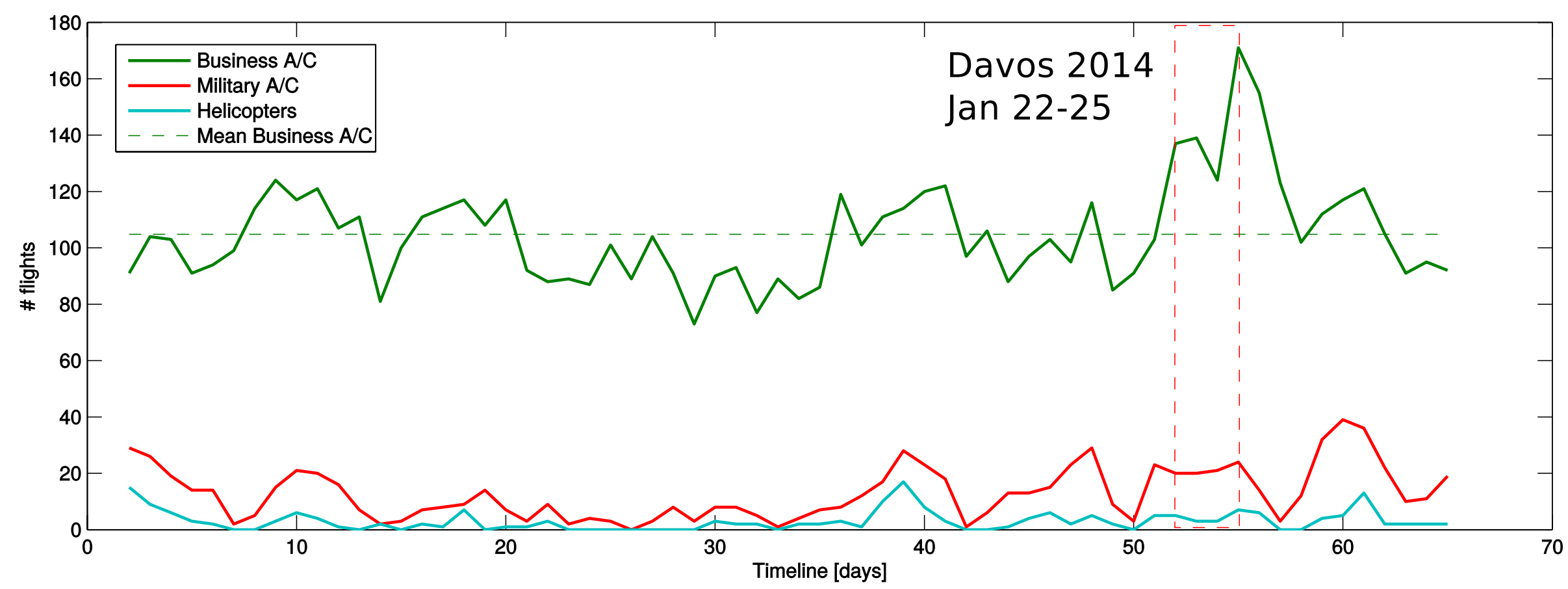




\section{Conclusion}

- OpenSky provides a scalable, open, and collaborative architecture for air traffic research.

- Communications security is an important problem in modern aviation.

- Our research using OpenSky proposes and analyses attack detection using several different approaches.

- Security and privacy has been OpenSky's main theme but the data is used for many other applications now.

- Check out http://opensky-network.org if you are interested further in air traffic communication research, security and non-security related. 


\section{References}

[1] "Lightweight Location Verification in Air Traffic Surveillance Networks", Martin Strohmeier, Vincent Lenders and Ivan Martinovic In Proceedings of the 1st ACM Workshop on Cyber-Physical System Security (CPSS '15). April, 2015.

[2] "Secure Track Verification", Matthias Schäfer, Vincent Lenders and Jens B Schmitt. In IEEE Symposium on Security and Privacy (S\&P). May 2015.

[3] "Intrusion Detection for Airborne Communication using PHY-Layer Information", Martin Strohmeier, Vincent Lenders and Ivan Martinovic. In Detection of Intrusions and Malware, and Vulnerability Assessment (DIMVA). July, 2015.

[4] "On Passive Data Link Layer Fingerprinting of Aircraft Transponders", Martin Strohmeier and Ivan Martinovic. In 1st ACM Workshop on Cyber-Physical Systems Security \& Privacy (CPS-SPC). October, 2015. 


\section{Questions?}

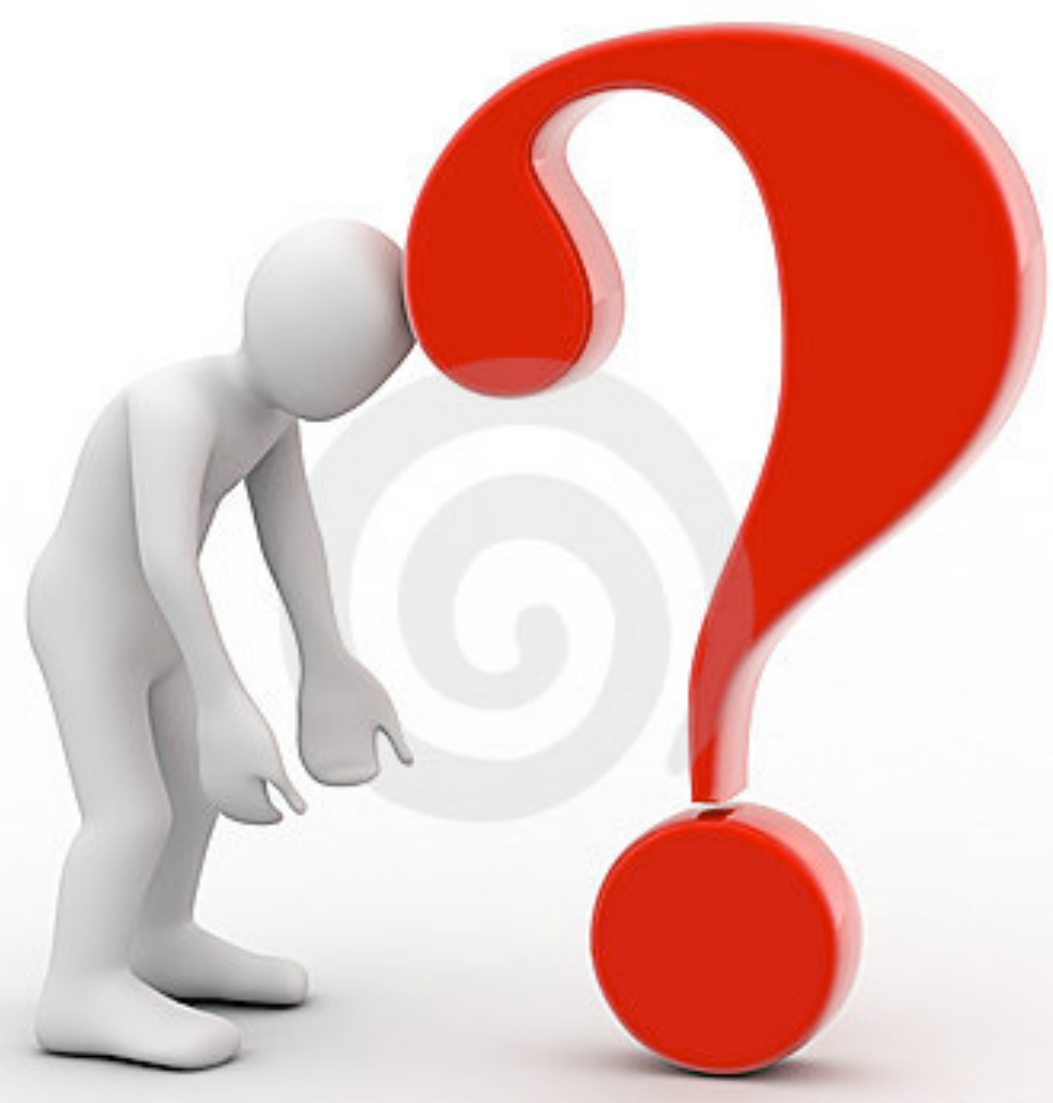

